\title{
Change in living arrangements following death of a partner in England and Wales, 1971 to 2001
}

Michael Hirst and Anne Corden

University of York

\begin{abstract}
Understanding trends and changes in the circumstances of couples separated by death is important for policy initiatives to reduce vulnerabilities associated with end of life care and for those who live on. This article uses widow(er)hood statistics and census data from the Office for National Statistics Longitudinal Study. It examines changes in couples' living arrangements and households at four successive censuses from 1971 to 2001 and shows how these differ by age and gender on the death of a spouse or partner. Findings draw attention to the effects of ageing and mortality improvements as well as wider social and economic trends in family and household formation, residential independence in older age, and policy developments on long-term care provision for older people.
\end{abstract}




\section{Contents}

Change in living arrangements following death of a partner in England and Wales, 1971 to 2001 130

Abstract 130

Introduction 132

Methods 132

Findings 133

Estimating the number of couples separated by death . 144

Conclusion 147

Acknowledgements 149

References.. 149 


\section{Introduction}

Ageing and mortality are major challenges for policy and political debate ${ }^{1}$. Accurate projections are required to inform health and social care provision, pension reform, and insurance based products such as mortgage protection and equity release schemes. Trends in ageing and mortality are also changing the needs and circumstances of dying and bereaved people.

Death of a spouse or partner represents perhaps the most convergent set of circumstances that shape experiences of both mortality and bereavement. Key determinants of partnership formation such as age, income and education influence mortality rates and changes in mortality rates. Moreover, what happens to people when their spouse or partner dies is closely linked to their circumstances and behaviour as a couple, and the life they shared together.

Couples' living arrangements have implications for the availability of care and support before and after the death of a partner. Wider consequences for the health and well-being of the partner who lives on and any children of the relationship include the financial and economic adjustments that follow the death ${ }^{2}$. This article examines trends and changes in the family and household composition of couples separated by death, and provides descriptive analyses by age and sex of the surviving partner. We also provide provisional assessments of how many couples were living apart and how many unmarried couples were cohabiting before separation by death.

\section{Methods}

We used data from official mortality statistics and from the Office for National Statistics Longitudinal Study (ONS LS) at four successive census points from 1971 to $2001^{3}$. The LS links census and vital registration records for around one per cent of the population of England and Wales $^{4}$. The original sample comprising approximately 500,000 individuals or 'LS members' was drawn from the 1971 census using four birth dates. Details of their circumstances have been updated with information collected in the 1981, 1991 and 2001 censuses. The sample is continually refreshed by the addition of one per cent of immigrants and births using the same birth dates, with further details of new entrants from subsequent censuses, and so remains nationally representative. Major strengths of the LS are its large sample size, low non-response and attrition rates, and inclusion of the institutional population. Limitations include the ten year gap between census enumerations, the restricted range of information collected at each census, changes over time in the definition and coding of key variables such as marital status, and differences between censuses in coverage and data quality.

Bereaved spouses are routinely identified by a trawl of the annual death files and linkage to the LS relies on matching their date of birth in the census record and the death register ${ }^{5}$. The register records legal marital status so death of a partner in the LS identifies widows and widowers, and does not cover cohabiting couples separated by death ${ }^{6}$. For the analysis described here, we constructed study groups before and after the death of a spouse, labelled pre-bereavement and post-bereavement cohorts respectively. Pre-bereavement cohorts included LS members present at a census whose spouse died within two years following that census; post-bereavement cohorts included LS members present at a census whose spouse had died less than two years before that census. A two year window either side of a census was a compromise between the need for sufficiently large cohorts for sub-group analysis, and the need to ensure that couples' circumstances reported in a census were not too far removed from those on separation by death. 
Pre-bereavement and post-bereavement cohorts were constructed from LS samples covering the 1981, 1991 and 2001 censuses; only a pre-bereavement cohort could be identified in 1971 because prior widow(er)hoods had not been added to the initial sample. Table 1 shows the number of people in each cohort. These comprised LS members usually resident in private households or communal establishments including, for example, a care home, hospice or hospital (apart from staff and relatives of staff) ${ }^{7}$. Sample numbers in the analysis varied because of missing or imputed information on relevant variables.

\section{Table 1 Number of bereaved LS women and men in the study design}

\begin{tabular}{llccc}
\hline Census & Cohort & Women & Men & Total \\
\hline 1971 & Pre-bereavement & 3120 & 1446 & 4566 \\
1981 & Pre-bereavement & 2773 & 1430 & 4203 \\
& Post-bereavement & 2595 & 1282 & 3877 \\
\multirow{2}{*}{1991} & Pre-bereavement & 2836 & 1347 & 4183 \\
& Post-bereavement & 2688 & 1229 & 3917 \\
2001 & Pre-bereavement & 2644 & 1267 & 3911 \\
& Post-bereavement & 2631 & 1133 & 3764 \\
\hline
\end{tabular}

Source: ONS Longitudinal Study

We evaluated the composition of bereavement cohorts for the impact of attrition and length of follow-up between the census and a spouse's death. We also examined apparent discrepancies in spouses' birth dates between the census record and the death register. Further details of the study design and these assessments are described elsewhere ${ }^{8}$.

\section{Findings}

In this section, we use census data collected from 1971 to 2001 to examine trends and changes in the circumstances of married couples at each census who were separated by death within the following two years. These findings are based on the socio-demographic profiles of LS members in the pre-bereavement cohorts described above. Where appropriate, we draw comparisons between their circumstances and those of LS widows and widowers at each census, from 1981 on, whose spouses had died during the previous two years. Comparisons between pre-bereavement and post-bereavement cohorts provide provisional indications of changes that might be associated with, or accompany, the death of a spouse. We then go on to evaluate the coverage of LS widow(er)hood statistics, which are based on death of a spouse, and estimate the number of couples, both married and cohabiting, separated by death in 2001 .

\section{Age and sex}

Death of a spouse is predominantly experienced by older people and now happens much later in the life course than in previous generations. In the early years of the 21 st Century, death of a spouse typically occurred when people were in their early 70 s, an increase of around six or seven years on three decades earlier (Table 2). The ageing of spousal bereavement may be due to increased health benefits associated with marriage as well as mortality improvements affecting all groups $^{9}$. The additional years lived by married people shown here exceed estimated increases of two to three years since 1981 in life expectancy for the general population at age $65^{10}$. 


\section{Table 2 Mean and median age of LS women and men on death of spouse, 1971-2001, England and Wales}

\begin{tabular}{|c|c|c|c|c|c|c|}
\hline & \multirow[b]{2}{*}{1971} & \multirow[b]{2}{*}{1981} & \multirow[b]{2}{*}{1991} & \multirow[b]{2}{*}{2001} & \multicolumn{2}{|c|}{$1971-2001$} \\
\hline & & & & & $\begin{array}{r}\text { Change } \\
\text { (years) }\end{array}$ & $\begin{array}{r}\text { Change } \\
\text { (per cent) }\end{array}$ \\
\hline \multicolumn{7}{|l|}{ Women } \\
\hline $\begin{array}{l}\text { Mean age } \\
\text { (SD) }\end{array}$ & $\begin{array}{r}63.1 \\
(11.5)\end{array}$ & $\begin{array}{r}65.5 \\
(11.5)\end{array}$ & $\begin{array}{r}68.1 \\
(11.3)\end{array}$ & $\begin{array}{r}69.3 \\
(11.7)\end{array}$ & 6.2 & 9.8 \\
\hline Median age & 64 & 67 & 69 & 71 & 7.0 & 10.9 \\
\hline \multicolumn{7}{|l|}{ Men } \\
\hline $\begin{array}{l}\text { Mean age } \\
\text { (SD) }\end{array}$ & $\begin{array}{r}65.6 \\
(12.1)\end{array}$ & $\begin{array}{r}67.8 \\
(12.3)\end{array}$ & $\begin{array}{r}70.1 \\
(11.8)\end{array}$ & $\begin{array}{r}71.9 \\
(12.4)\end{array}$ & 6.3 & 9.6 \\
\hline Median age & 67 & 70 & 71 & 74 & 7.0 & 10.4 \\
\hline \multicolumn{7}{|c|}{ Base numbers } \\
\hline Women & 3120 & 2773 & 2836 & 2644 & - & - \\
\hline Men & 1446 & 1430 & 1347 & 1267 & - & - \\
\hline
\end{tabular}

Source: ONS Longitudinal Study

Sex differences in spousal bereavement reflect the tendency for women to marry men older than themselves. Women were typically three years younger than their husband although marital age differences of two years or less were most common across the bereavement cohorts. Similarly, women were bereaved around two to three years younger on average than their male counterparts (Table 2). For women and men alike however, increases in the age at which couples were separated by death have boosted the proportion of people bereaved in their 70 s and beyond (Figure 1). In the 24 months following the 2001 census, 57 per cent of women were aged 70 and over when their spouse died, up from 33 per cent in an equivalent period following the 1971 census. Comparable figures for bereaved men were 64 and 44 per cent respectively.

The age difference at marriage and women's longer life expectancy largely account for the predominance of widows among bereaved spouses. Overall, twice as many women as men experienced the death of a spouse and while that ratio fluctuated a little, there was no firm trend across these cohorts. Sex differences in spousal bereavement were substantial in all but the oldest old, such that men in their 80 s and older were almost as likely as women to experience the death of a spouse (Figure 2). However, the ratio of widows to every 100 widowers appears to have increased in older age groups since the early 70 s although this may reflect improvements in the identification of LS women following death of a spouse ${ }^{5}$. 


\section{Figure 1 Percentage age distribution of LS men and women on death of spouse, 1971 and 2001, England and Wales}
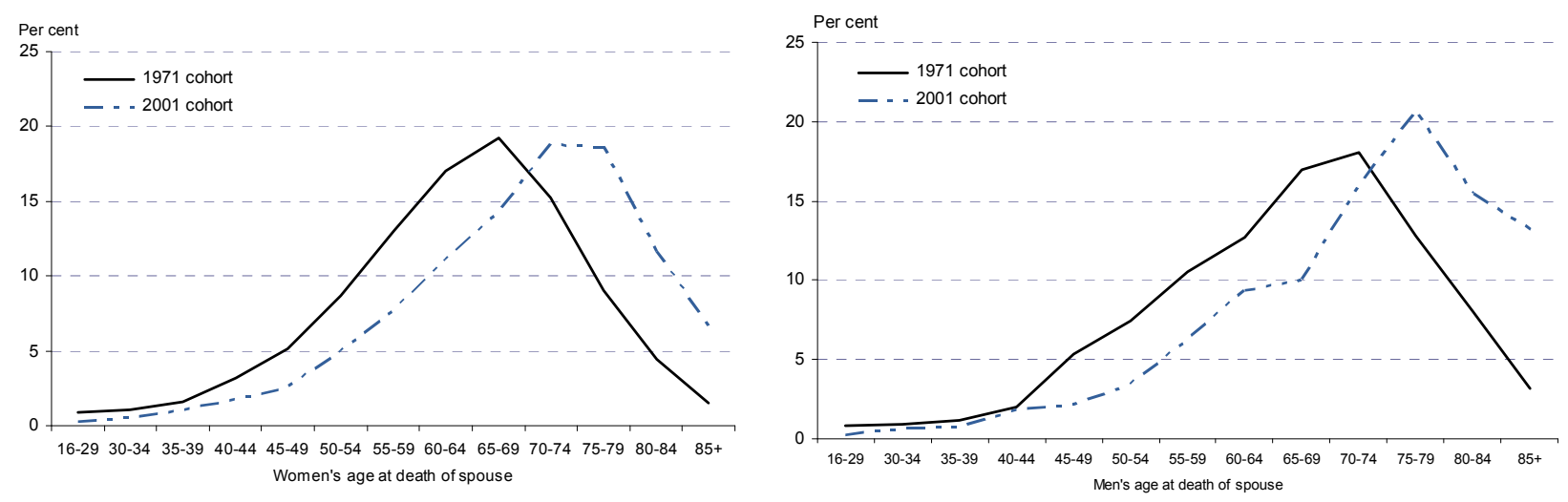

Source: ONS Longitudinal Study

\section{Figure 2 Sex ratio of LS members by age on death of spouse, 1971 and 2001, England and Wales}

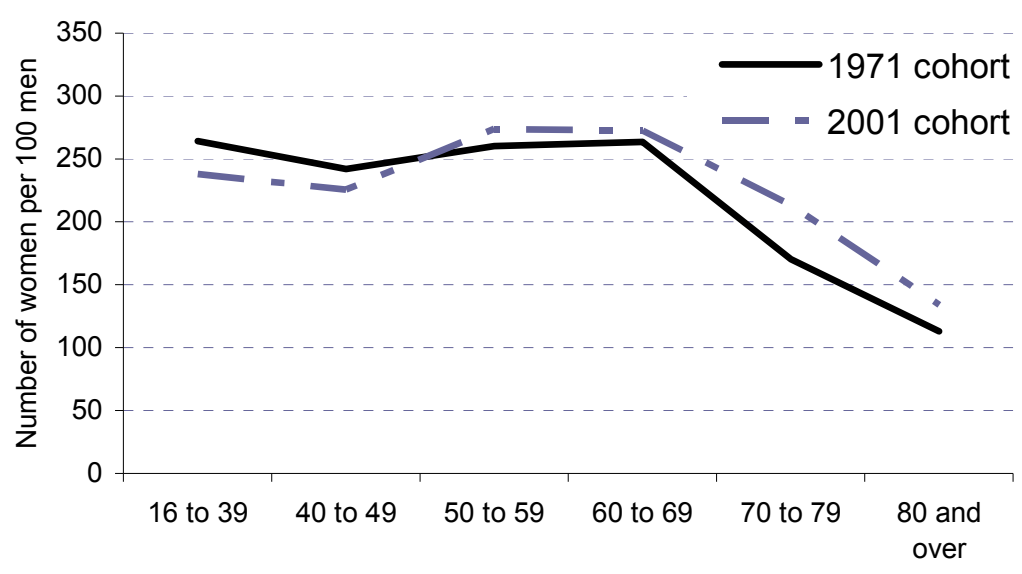

Age on death of spouse

\section{Living arrangements}

As might be expected, most people were living with their marital partner at the census before their spouse died. That proportion declined between 1971 and 2001, from 96 to 91 per cent, especially in older age groups (Figure 3). Several factors would account for couples apparently not living together before one spouse died. Their older age profile might indicate that admission of the LS member to institutional care was one such reason (see further below). The contribution of other factors is less clear as the circumstances of 'absent spouses' are not recorded. Some couples may have lived apart because they had separated though still formally married. Some spouses may have entered institutional care; they would not have been counted as co-resident even if they lived in the same establishment as the LS member to whom they were married. Some cohabiting couples and LS members apparently living alone may have married their partner shortly after the census, before separation by death. However, spouses working away from home or serving in the armed forces should have been treated as usually co-resident. 


\section{Figure 3 LS members by age living with a spouse before separation by death, 1971 and 2001, England and Wales}

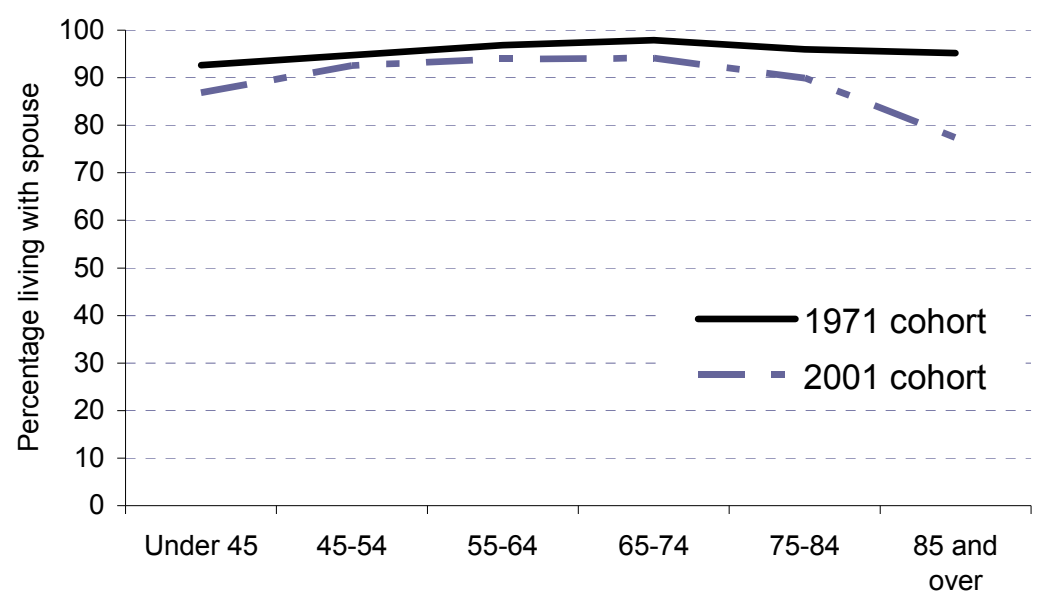

Age on death of spouse

Source: ONS Longitudinal Study

Information on living arrangements gathered in 1991 and 2001 shows very few couples living as unmarried cohabitants before the death of a spouse; there were probably fewer in earlier decades when cohabitation was less widespread (Table 3). Apart from married couples then, people were mostly living singly at the census before the death of a spouse and their numbers increased slightly between 1991 and 2001. Their partnership status is uncertain although all had, or would have, a spouse who died within two years of the census.

Table 3 shows further that few people in the post-bereavement cohorts had apparently repartnered in the first year or so after their spouse died ${ }^{11}$. Bereaved men were somewhat more likely to be married or cohabiting than bereaved women although women and men under 65 were more likely to have re-partnered than those who were older (women 3.1 and 0.8 per cent respectively, men 5.6 and 1.9 per cent respectively in the 2001 cohort). Re-partnering after the death decreased between the 1991 and 2001 cohorts, associated with a decline in formal remarriage. However, partnership rates remained steady among bereaved women under 65 (3.2 and 3.1 per cent in 1991 and 2001 respectively) but declined among men (8.4 and 5.6 per cent respectively). Among bereaved people aged 65 and over, partnership rates fell by half between the two cohorts for women and men alike.

As noted above, some couples were living apart before separation by death because one or both spouses had entered institutional care. The extent of institutional living, for LS members only, is shown in Table 4, which mirrors wider trends pointing to a rise in admissions during the 1980s followed by a levelling off thereafter. Death of a spouse may itself influence the volume, pattern and timing of institutional admissions. Although few people were recorded in such settings, more LS members lived in communal establishments after their spouse died than in the prebereavement cohorts. 


\section{Table 3 Living arrangements of LS women and men before and after death of spouse, 1991 and 2001, England and Wales}

\begin{tabular}{lrrrr}
\hline Percentages & \multicolumn{2}{c}{ Pre-bereavement } & \multicolumn{2}{c}{ Post-bereavement } \\
& $\mathbf{1 9 9 1}$ & $\mathbf{2 0 0 1}$ & $\mathbf{1 9 9 1}$ & $\mathbf{2 0 0 1}$ \\
\hline Women & & & & \\
$\quad$ Single/lone parent & 4.3 & 5.9 & 97.5 & 98.5 \\
$\quad$ Married couple & 95.2 & 93.3 & 2.1 & 0.9 \\
$\quad$ Cohabiting couple & 0.5 & 0.7 & 0.3 & 0.6 \\
Men & & & & \\
$\quad$ Single/lone parent & 3.8 & 5.7 & 94.8 & 97.2 \\
$\quad$ Married couple & 95.6 & 92.5 & 3.7 & 1.7 \\
$\quad$ Cohabiting couple & 0.7 & 1.8 & 1.4 & 1.1 \\
Base numbers & & & & \\
$\quad$ Women & 2788 & 2599 & 2610 & 2531 \\
$\quad$ Men & 1327 & 1248 & 1178 & 1087 \\
\hline
\end{tabular}

Note: percentage LS members in private households; data on cohabitation is not available for 1971 and 1981.

Source: ONS Longitudinal Study Table 4 LS women and men living in communal establishments before
and after death of spouse, 1971-2001, England and Wales

\begin{tabular}{lrrrr}
\hline Percentages & 1971 & 1981 & 1991 & 2001 \\
\hline Women & & & & \\
$\quad$ Pre-bereavement & 0.3 & 0.4 & 1.5 & 1.7 \\
$\quad$ Post-bereavement & - & 1.8 & 2.7 & 3.7 \\
Men & & & & \\
$\quad$ Pre-bereavement & 0.2 & 0.8 & 1.3 & 1.4 \\
$\quad$ Post-bereavement & - & 1.4 & 4.1 & 4.1 \\
& & & & \\
Base numbers & & & & \\
Women & 3119 & 2773 & 2836 & 2643 \\
$\quad$ Pre-bereavement & $n / a$ & 2594 & 2688 & 2629 \\
$\quad$ Post-bereavement & & & & \\
Men & 1446 & 1429 & 1347 & 1266 \\
$\quad$ Pre-bereavement & $n / a$ & 1280 & 1229 & 1133 \\
$\quad$ Post-bereavement & & & & \\
\hline
\end{tabular}

Source: ONS Longitudinal Study

Almost all the LS members living in communal establishments (99 per cent), in both pre-

bereavement and post-bereavement cohorts, were aged 65 and over; however, the oldest old were most likely to be recorded in such settings. People aged 75 and over also showed the largest uptake, relative to pre-bereavement levels, in institutional living after the death of a spouse (Fig 4).

\section{Household composition}

Trends in couples' living arrangements before separation by death have contributed to a decline in multi-generational households. Since the 1980s such couples were less likely to be looking after children and young people under 16, or young people under 18 and still at school or college.

Trends in the proportion of couples living with parents were less clear-cut but point to a decline in 
the 1990s (Table 5). The increasing age of spousal bereavement may have influenced both these trends, meaning that any children were more likely to have been counted as adults and left the parental home, and parents of older couples were more likely to have died or entered institutional care.

\section{Figure 4 LS members by age living in communal establishments before and after death of spouse, 1981-2001, England and Wales}

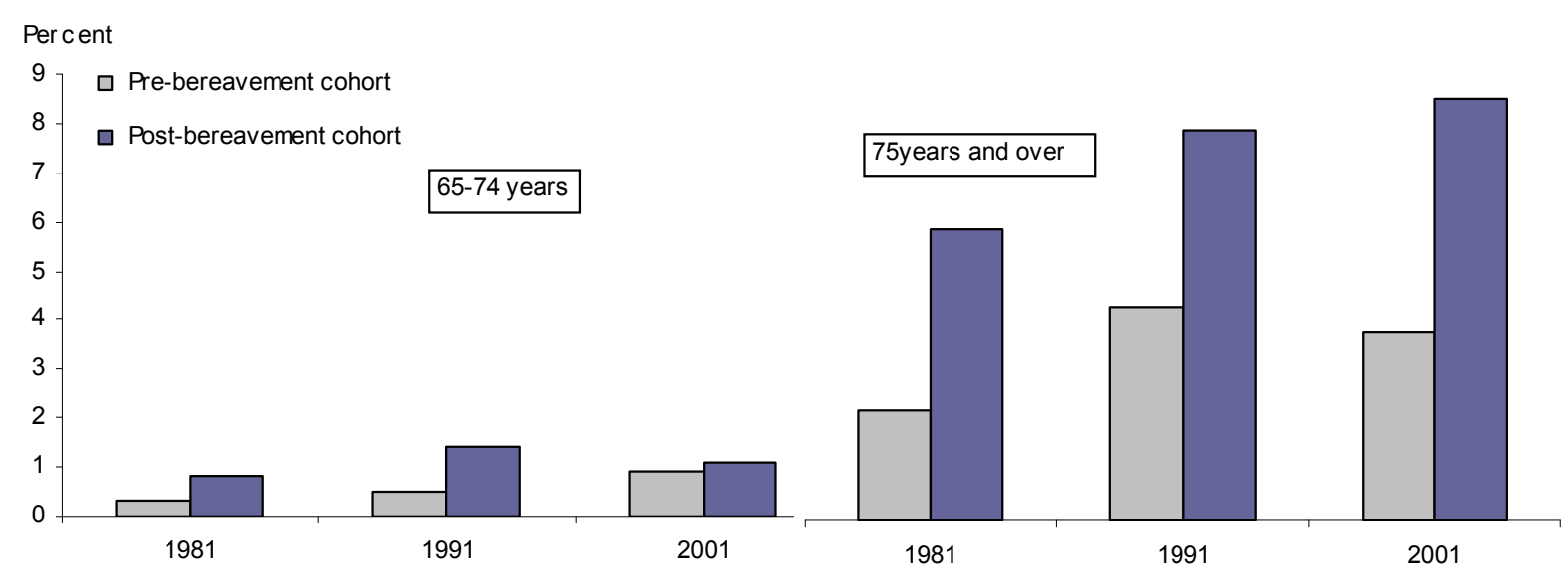

Table 5 LS women and men living with dependent children or parents before death of spouse, 1971-2001, England and Wales

\begin{tabular}{lrrrr}
\hline Percentages & 1971 & 1981 & 1991 & $\mathbf{2 0 0 1}$ \\
\hline $\begin{array}{l}\text { Dependent children in the family } \\
\text { Women }\end{array}$ & 18.5 & 18.3 & 14.4 & 13.1 \\
$\quad$ Men & 22.5 & 26.8 & 17.2 & 17.9 \\
Parents in the household & & & & \\
$\quad$ Women & $\mathrm{n} / \mathrm{a}$ & 2.8 & 2.4 & 0.9 \\
Men & $\mathrm{n} / \mathrm{a}$ & 3.1 & 2.9 & 0.0 \\
Base numbers & & & & \\
$\quad$ Women & 1667 & 1266 & 1023 & 780 \\
$\quad$ Men & 640 & 523 & 408 & 302 \\
\hline
\end{tabular}

Note: percentage LS members under 65 in private households; includes step children and step parents in 2001 only. Source: ONS Longitudinal Study

Despite an overall trend towards single generation households, family composition when one spouse died continued to reflect typical life cycle stages. Most people under 45, and sizeable minorities of those between 45 and 54 , would have had responsibility for looking after children and young people before and after their spouse died (Figure 5). However, the proportion of younger couples with children fluctuated somewhat between 1971 and 2001 and showed a net decline within the age groups used here. 


\section{Figure 5 LS members by age living with dependent children before death of spouse, 1971-2001, England and Wales}

Per cent

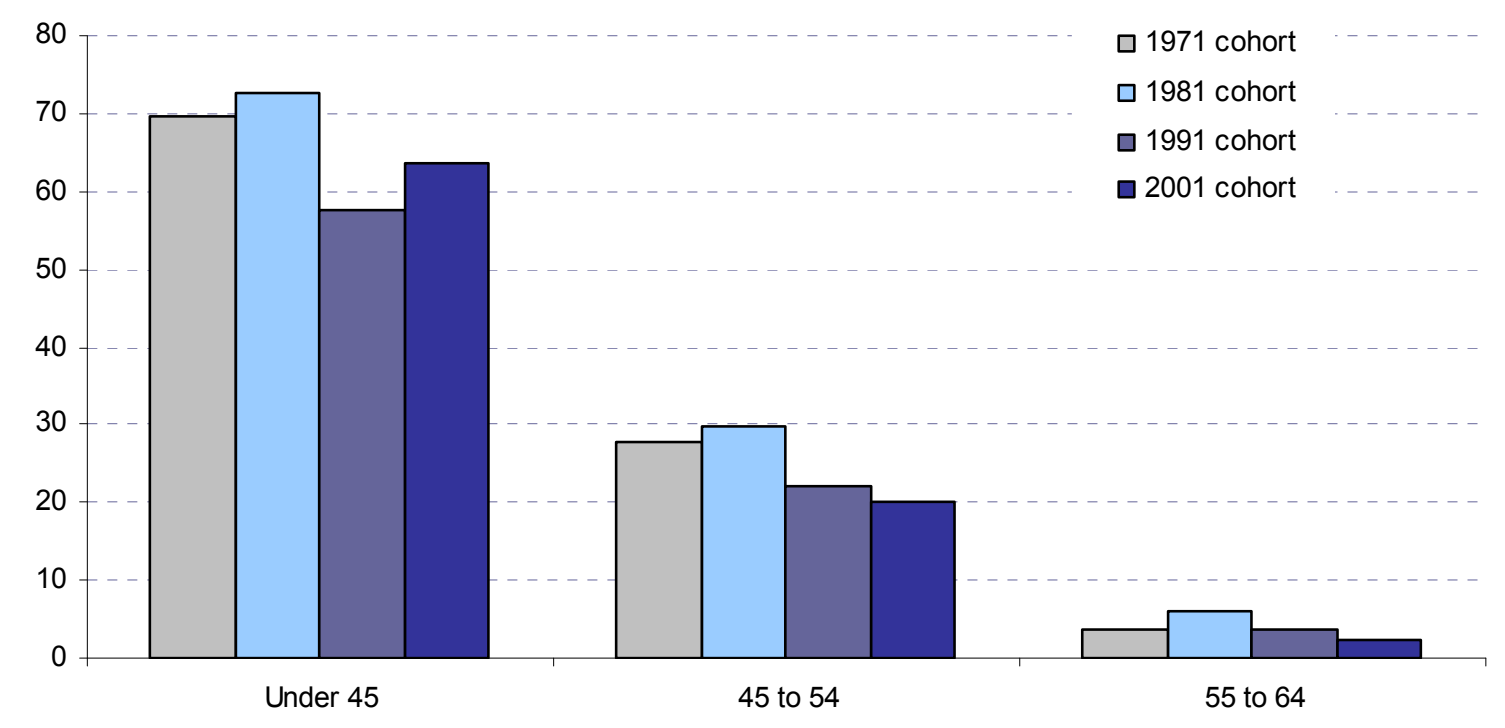

Note: percentage LS members in private households.

Source: ONS Longitudinal Study

At the same time, there was a marked decline in people living with adult children before their spouse died: the proportion in such households in 2001 was almost half that of the early 1980s (Table 6). The impact was most noticeable among the oldest old, reflecting the increasing trend for older people not to live in the same household as their adult children (Figure 6). As might be expected, couples aged 45 to 54 were most likely to be living with adult children indicating that death of a spouse in middle age often occurred when children were entering adult life and relationships, and establishing their own working careers.

Death of a spouse may itself influence inter-generational living, perhaps linked to the support and accommodation needs of the one who lives on. Findings show an increased propensity, across the age range, to live with adult children after the death. How that situation arose - who moved and when - cannot be determined from these data. Table 6 shows that differences in proportions between pre-bereavement and post-bereavement cohorts have changed little since the early 1980 s, indicating that the impact of a spouse's death on sharing accommodation with adult children has not diminished. With each successive cohort however, fewer people were living with adult children following the death of a spouse. 


\section{Table 6 LS women and men living with adult children before and after death of spouse, 1981-2001, England and Wales}

\begin{tabular}{lccr}
\hline & 1981 & 1991 & $\mathbf{2 0 0 1}$ \\
\hline Women & & & \\
$\quad$ Pre-bereavement & 19.4 & 16.6 & 10.8 \\
$\quad$ Post-bereavement & 22.3 & 19.9 & 14.6 \\
Men & & & \\
$\quad$ Pre-bereavement & 17.3 & 16.2 & 9.1 \\
Post-bereavement & 19.2 & 17.8 & 13.5 \\
Base & & & \\
Women & & & \\
$\quad$ Pre-bereavement & 2761 & 2793 & 2354 \\
$\quad$ Post-bereavement & 2548 & 2615 & 2459 \\
Men & & & \\
$\quad$ Pre-bereavement & 1418 & 1330 & 1140 \\
Post-bereavement & 1262 & 1179 & 1053 \\
\hline
\end{tabular}

Note: percentage LS members in private households; data not available for 1971.

Source: ONS Longitudinal Study

Figure 6 LS members living with adult children before and after death of spouse by age, 1981 and 2001, England and Wales

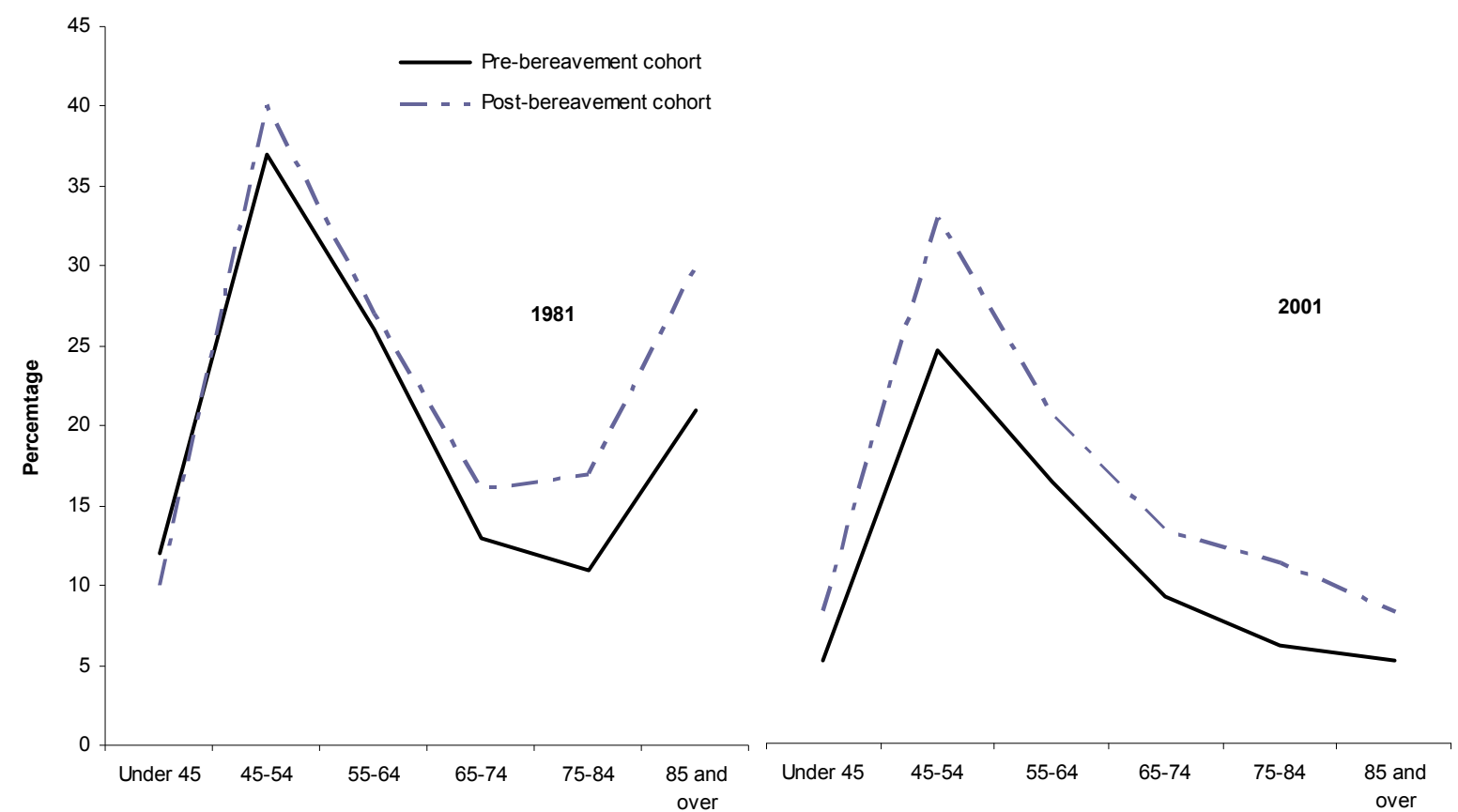

Note: percentage LS members in private households.

Source: ONS Longitudinal Study 


\section{Household size}

Changes in living arrangements and household formation have contributed to a rise in the extent to which couples lived on their own before separation by death. The proportion of two person households rose by over ten percentage points in the thirty years to 2001 , with much of the increase occurring in the 1970s and 1980s (Table 7). There was a much smaller increase in the number of people living on their own probably reflecting, as suggested above, admission of a spouse into institutional care.

As a consequence, a substantial majority of people lived alone following the death of a spouse. Living alone was most prevalent among older widows and widowers and has become more widespread with each succeeding cohort (Figure 7).

\section{Table 7 LS women and men by number of people in household before and after death of spouse, 1971-2001, England and Wales}

\begin{tabular}{lrrrrrrr}
\hline & \multicolumn{3}{l}{ Pre-bereavement } & & \multicolumn{3}{c}{ Post-bereavement } \\
& $\mathbf{1 9 7 1}$ & $\mathbf{1 9 8 1}$ & $\mathbf{1 9 9 1}$ & $\mathbf{2 0 0 1}$ & $\mathbf{1 9 8 1}$ & $\mathbf{1 9 9 1}$ & $\mathbf{2 0 0 1}$ \\
\hline Women & & & & & & & \\
1 & 0.7 & 0.9 & 2.9 & 4.2 & 63.0 & 72.4 & 75.7 \\
2 & 64.0 & 69.6 & 74.7 & 75.5 & 21.3 & 17.1 & 14.8 \\
3 & 19.4 & 17.0 & 14.1 & 13.0 & 8.5 & 6.3 & 6.0 \\
4 or more & 15.9 & 12.4 & 8.3 & 7.2 & 7.3 & 4.3 & 3.5 \\
Men & & & & & & & \\
1 & 0.8 & 1.6 & 2.8 & 4.7 & 63.2 & 71.6 & 76.2 \\
2 & 63.1 & 70.4 & 74.5 & 76.0 & 20.0 & 17.0 & 14.6 \\
3 & 20.4 & 15.4 & 14.4 & 11.5 & 9.0 & 5.6 & 5.4 \\
4 or more & 15.8 & 12.6 & 8.3 & 7.8 & 7.8 & 5.8 & 3.8 \\
Base & & & & & & & \\
$\quad$ Women & 3111 & 2761 & 2793 & 2599 & 2548 & 2615 & 2531 \\
Men & 1443 & 1418 & 1330 & 1248 & 1262 & 1179 & 1087 \\
\hline
\end{tabular}

Note: percentage LS members in private households; post-bereavement cohort not available in 1971.

Source: ONS Longitudinal Study 


\section{Figure 7 Percentage of LS members by age living alone after death of spouse, 1981-2001, England and Wales}

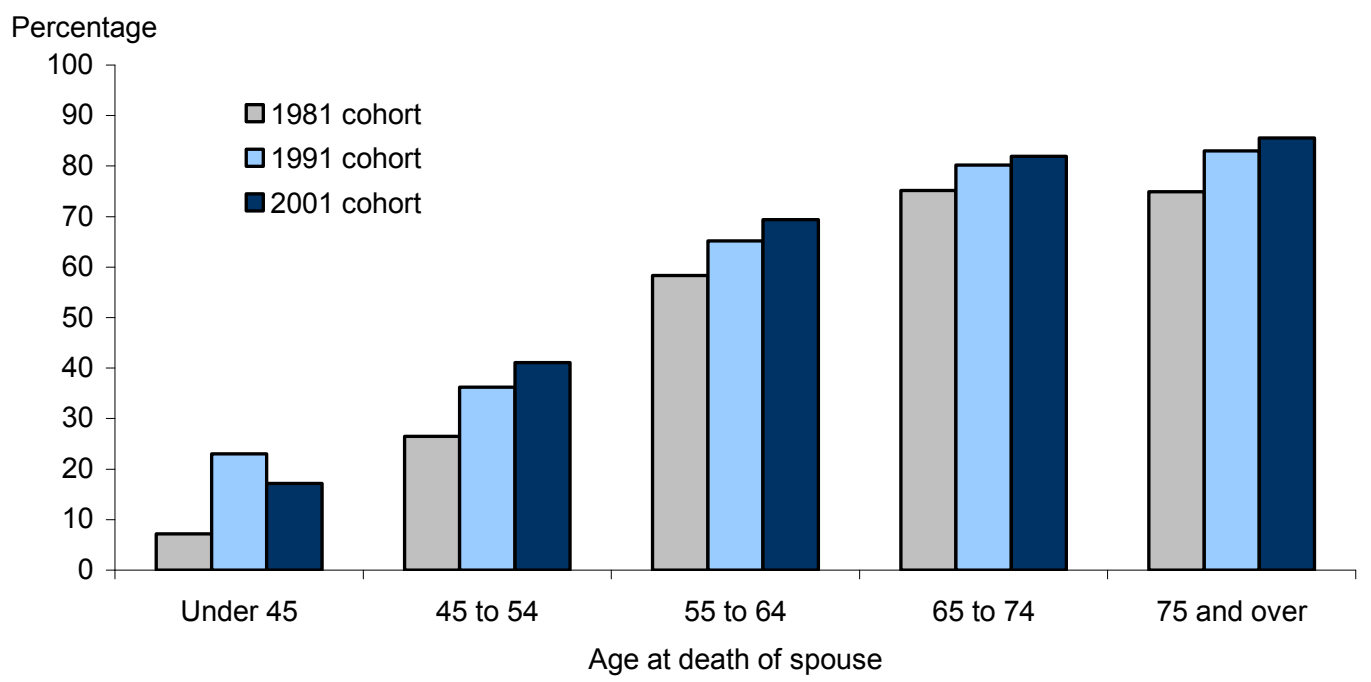

Note: percentage LS members in private households.

Source: ONS Longitudinal Study

\section{Residential mobility}

Changes in living arrangements and household composition following the death of a spouse may result from people moving to join another household or being joined by new household members. Moving house may be linked to changes in people's accommodation and support needs: to downsize, release equity, or to be nearer friends and family, for example. Findings indicate that such moves were not widespread and may have decreased over time. However, it was not possible to count recent moves into institutional care which can be identified in the LS only by comparing residential location at successive censuses.

Table 8 shows that bereaved people were somewhat more likely to have moved house in the past year than those living in private households before separation by death. These comparisons may overstate the impact of a spouse's death on moving house because people in post-bereavement cohorts could have moved before the death if their spouse had died less than 12 months before a census, that is, within the set period for reporting a change of address. Taking account of this time frame did not alter the broad conclusion that residential mobility was probably more widespread after the death. People whose spouse died more than 12 months before a census were somewhat more likely to have moved house in the past year than those whose spouse died within 12 months of a census (6.2 and 4.9 per cent respectively in the 2001 post-bereavement cohort). 


\section{Table 8 LS women and men who changed address in year before and after death of spouse, 1981-2001, England and Wales}

\begin{tabular}{lrrr}
\hline & 1981 & $\mathbf{1 9 9 1}$ & $\mathbf{2 0 0 1}$ \\
\hline Women & & & \\
Pre-bereavement & 3.5 & 3.2 & 3.3 \\
Post-bereavement & 7.1 & 4.6 & 5.8 \\
Men & & & \\
Pre-bereavement & 3.5 & 1.7 & 3.5 \\
Post-bereavement & 6.3 & 4.7 & 5.3 \\
Base numbers & & & \\
Women & & & \\
$\quad$ Pre-bereavement & 2761 & 2793 & 2421 \\
Post-bereavement & 2548 & 2615 & 2374 \\
Men & & & \\
$\quad$ Pre-bereavement & 1418 & 1330 & 1204 \\
Post-bereavement & 1262 & 1179 & 1025 \\
\hline
\end{tabular}

Note: percentage LS members in private households; data not available for 1971.

Source: ONS Longitudinal Study

Trends in residential mobility may be influenced by changes in the housing market, including legislation in the 1980s which enabled public sector tenants to purchase their home at discounted prices. From 1981 to 2001, residential mobility increased somewhat among people under 55 and declined slightly in older age groups (Figure 8). These findings may reflect increased home ownership in older age groups and preferences for staying put, as well as the often drawn out process of buying and selling a house. Home owners were half as likely as those in rented accommodation to have moved house following the death of a spouse prior to the 2001 census: an odds ratio of 0.48 compared with 0.86 and 0.57 in the 1981 in 1991 post-bereavement cohorts respectively.

\section{Figure 8 LS members by age who changed address in the year before and after death of spouse, 1981-2001, England and Wales}

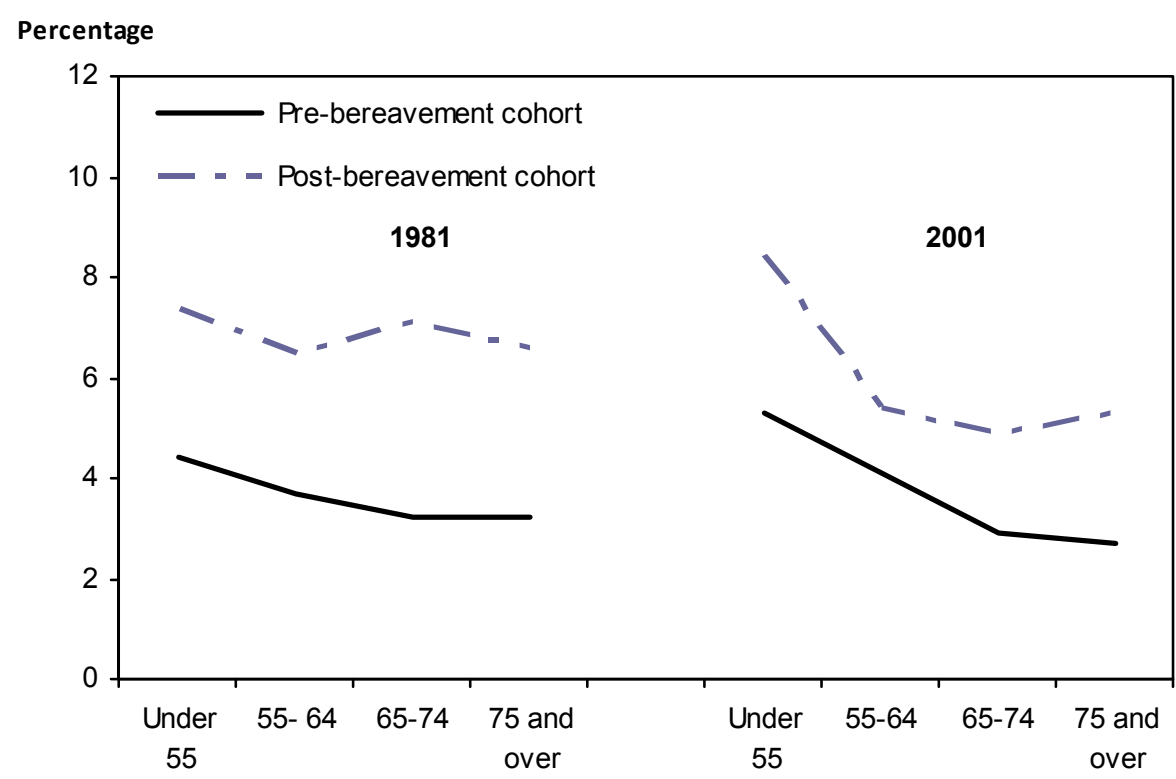


These findings shed some light on the timing of residential moves following the death of a spouse. One year migration rates in the 1991 and 2001 cohorts were around five per cent, only marginally above pre-bereavement levels (Table 8 ). Though not directly comparable, more than a third of widows and widowers aged 50 and over changed their address between 1991 and $2001^{12}$. These comparisons between one year and ten year migration rates indicate that most residential moves following the death of a spouse probably occurred several years after the death, rather than in the first 12 months or so.

\section{Estimating the number of couples separated by death}

So far we have focused on married couples and the circumstances of LS members before and after their spouse died. Their identification was based on reported marital status when a death is registered. These data provide a useful starting point for estimating the incidence of spousal bereavement. However, they misrepresent the number of couples separated by death because the classification of marital status has yet to reflect the diversity of family forms. Separated, unmarried cohabitation, same sex partnerships, and 'living apart together' are not currently recognised in the registration process. As a consequence, some people recorded as married at the time of death may not have been in a relationship or not married to the partner with whom they were living; and some people recorded as single, widowed or divorced may have been living with a partner.

By examining the living arrangements of LS members before they died (rather than, as above, before their spouse died), it is possible to gain some indication of how many were married or living as married from census records. Table 9 compares the census defined marital status of LS members who died within two years following the 2001 census with the marital status record on the registration of their death. The table is organised according to whether or not LS members said they were living with a partner at the time of the census, distinguishing between married and cohabiting couples.

Reports of marital status and partnership histories are not always reliable or easy to interpret and comparison of individuals' reported marital status in census and death records reveals both expected and unexpected shifts. Thus, Table 9 shows that 174 people in a married couple at the time of the census were recorded as widowed when they died indicating, quite plausibly, that their spouse may have died before them. Among cohabiting couples, a decrease in the number of divorced or single people, matched by an increase in the number of married people, similarly draws attention to a plausible change in their legal marital status before separation by death. Changes in marital status of those in communal establishments are perhaps least reliable because details registered on death may have been informed by members of staff rather than close relatives. They indicate a decrease in the number of married people that, on the face of it, was associated with an increase in those regarded as divorced or single, but no increase in the widowed group.

Differences in reported marital status between the census record and registration of death can be used, with caution, to inform assumptions about the marital status of couples separated by death. One set of assumptions (described in Box one) indicates that 4,391 people might have been part of a couple, though not necessarily co-resident, when they died. This figure is somewhat higher than the 4,301 recorded as married on death, suggesting that official mortality statistics represent 
around 98 per cent of couples where one partner died. Other assumptions would produce different estimates.

That 98 per cent of couples separated by death were probably legally married may be compared with an estimated 96 per cent derived from the British Household Panel Survey (BHPS), explained in Box two. The true estimate may lie between these two figures. The LS figure is probably an overestimate because it excludes same sex couples. The BHPS is probably an underestimate because some cohabitants could have married before their partner died some six months on average after the interview. In addition, the BHPS does not identify couples where one or both partners were in a communal establishment at the date of death. Neither source fully counts couples that usually live apart.

Whatever the limitations of the LS and BHPS data sets, the number of couples where one partner dies is probably higher than indicated by those recorded as married when death is registered, mainly because registration fails to take account of unmarried cohabitation. In 2001 over 203,000 people in England and Wales were recorded as married on registration of their death ${ }^{13}$. Applying a midpoint estimate between the LS and BHPS estimates, that 97 per cent of couples separated by death were legally married, produces an additional 6,000 couples who were cohabiting when one partner died, making almost 210,000 couples altogether. These estimates provide a starting point for further investigation and comparison with other longitudinal data sets.

\section{Box one Partnerships on separation by death}

From Table 9, we may assume that those in a couple comprised the following:

- 3,890 people in a married couple at the census and recorded as married at death.

- 238 people in a cohabiting couple at the census. This may be an overestimate if cohabitation happens to be a relatively transitory arrangement.

- 54 people representing the net increase in the number of individuals and lone parents recorded as married between the census and date of death. This figure may underestimate the extent of re-partnering in this group through unmarried cohabitation.

- 209 married people who were living in communal establishments at the census.

These figures together indicate that 4,391 LS members might have been part of a couple when they died. 


\section{Table 9 Living arrangements of LS members in 2001 by marital status at census and at date of death, England and Wales}

\begin{tabular}{|c|c|c|}
\hline & $\begin{array}{l}\text { April } 2001 \\
\text { at census }\end{array}$ & $\begin{array}{r}\text { Died before } \\
1 \text { May } 2003\end{array}$ \\
\hline \multicolumn{3}{|c|}{ Married couple } \\
\hline Single & 0 & 5 \\
\hline Married & 4089 & 3890 \\
\hline Widowed & 0 & 174 \\
\hline Divorced & 0 & 9 \\
\hline Separated & 3 & $\mathrm{n} / \mathrm{a}$ \\
\hline Not stated & $\mathrm{n} / \mathrm{a}$ & 14 \\
\hline Total & 4092 & 4092 \\
\hline \multicolumn{3}{|c|}{ Cohabiting couple } \\
\hline Single & 51 & 46 \\
\hline Married & 19 & 51 \\
\hline Widowed & 50 & 51 \\
\hline Divorced & 104 & 87 \\
\hline Separated & 14 & $\mathrm{n} / \mathrm{a}$ \\
\hline Not stated & $\mathrm{n} / \mathrm{a}$ & 3 \\
\hline Total & 238 & 238 \\
\hline \multicolumn{3}{|c|}{ Individual or lone parent } \\
\hline Single & 743 & 739 \\
\hline Married & 97 & 151 \\
\hline Widowed & 3272 & 3268 \\
\hline Divorced & 455 & 478 \\
\hline Separated & 100 & $\mathrm{n} / \mathrm{a}$ \\
\hline Not stated & $\mathrm{n} / \mathrm{a}$ & 31 \\
\hline Total & 4667 & 4667 \\
\hline \multicolumn{3}{|c|}{ Communal establishment } \\
\hline Single & 288 & 307 \\
\hline Married & 240 & 209 \\
\hline Widowed & 1394 & 1375 \\
\hline Divorced & 66 & 90 \\
\hline Separated & 7 & $\mathrm{n} / \mathrm{a}$ \\
\hline Not stated & $\mathrm{n} / \mathrm{a}$ & 14 \\
\hline Total & 1995 & 1995 \\
\hline \multicolumn{3}{|c|}{ All living arrangements } \\
\hline Single & 1082 & 1097 \\
\hline Married & 4445 & 4301 \\
\hline Widowed & 4716 & 4868 \\
\hline Divorced & 625 & 664 \\
\hline Separated & 124 & $\mathrm{n} / \mathrm{a}$ \\
\hline Not stated & $\mathrm{n} / \mathrm{a}$ & 62 \\
\hline Total & 10992 & 10992 \\
\hline
\end{tabular}

Notes:

'n/a' means the category was not available.

'Married' includes those who have remarried.

'Single' means never married.

Separated but legally married' could be recorded only in the census.

'Not stated' could be recorded only at registration of death.

Source: ONS Longitudinal Study 


\section{Box two Estimating the number of couples separated by death using the British Household Panel Survey}

The BHPS is a nationally representative survey of private households and aims to interview the same people every year ${ }^{1}$. Panel deaths between successive interview waves from 1991 to 2004 identified 756 people whose partner died ${ }^{2}$. Of these, 27 people (four per cent) said they were cohabiting when interviewed before their partner's death, including two people who lived with partners of the same sex. These interviews took place around six months on average before the death $(S D=4)$.

1. Lynn P (ed.) (2006) Quality Profile: British Household Panel Survey Version 2.0: Waves 1 to 13: 1991-2003. Institute for Social and Economic Research, University of Essex, Colchester.

2. Corden A, Hirst M and Nice K (2008) The Financial Implications of Death of a Partner. Social Policy Research Unit, University of York, York.

\section{Conclusion}

People whose spouse died in the early years of the 21st century were generally older than their counterparts three decades earlier. Over the same period, the number of married couples separated by death in England and Wales has progressively fallen ${ }^{14}$. Longer life expectancy has been a key driver of these trends although the closing gender gap in mortality improvements has had little impact so far on reducing the predominance of widows among bereaved spouses. For men and women alike however, death of a spouse is mostly experienced in the context of a long life course and increasingly shaped by the circumstances and transitions associated with older age.

The ageing of spousal bereavement has, in turn, influenced couples' family and household circumstances before separation by death. Fewer couples were living with adult children, younger children or elderly parents. Across the study period, couples were increasingly living on their own before separation by death, accompanied by a small but rising number of older people living alone or in communal establishments before their spouse died. Among other factors, wider trends in family and household formation, residential independence in older age, and policy developments on long-term care provision for older people have shaped changes in couples' circumstances. Moreover, stage in the family life cycle was an important determinant of couples' living arrangements before one spouse died although examination of partnership histories was beyond the scope of the data used here.

Following bereavement, most people lived alone, especially in older age groups, signifying for many the adjustment to loss and changes to status or role that follow the death of a spouse. For some, entry to institutional care or living with adult children may be triggered by the death of a spouse. Although residential mobility appears to be associated with widow(er)hood, moving house may not take place until several years after the death, prompted by less direct or immediate consequences of bereavement including changes in health and mobility, income or accommodation needs. 
The number of couples separated by death is expected to rise in coming decades as the post-war baby boomer generations enter older age groups. Population projections show deaths increasing throughout much of the 21 st Century ${ }^{15}$, while the number of people aged 65 and over living in married or cohabiting couples is expected to increase from under five million to over eight million between 2007 and $2031^{16}$.

Needs for practical and emotional support for dying and bereaved people may increase accordingly, fuelling debate about risk factors for complicated or prolonged grief and targeting effective interventions. Trends in ageing, mortality and living arrangements may mean more couples reaching older age with diminished resources and capabilities to manage the care and support needs of a partner approaching the end of life, and cope with the transitions and adjustments that follow. Death, dying and bereavement present clear entry points for limiting or preventing social, economic and health vulnerabilities ${ }^{17}$. Additionally, a new legal framework would help protect the property rights and financial well-being of unmarried and unregistered couples, their children and other home sharers ${ }^{18}$.

Trends and changes in couples' living arrangements before separation by death are key elements in projecting demand for and spending on adult social care, welfare assistance, and long-term care for older people. Information on their circumstances is important for policy development, service delivery and professional practice to support people through this period.

\section{Key findings}

Based on married couples at each census, 1971 to 2001, who were separated by death within the following two years, and the circumstances of widows or widowers at each census, from 1981 on, who had been bereaved during the previous two years, this study found that:

- Age on death of a spouse increased by almost seven years between the early 1970 s and the first years of the 21st Century (from around 65 to 72 median ages). Nearly three out of four people (72 per cent) were aged 65 and over when their spouse died, up from 52 per cent three decades earlier.

- Couples increasingly lived on their own before separation by death: 76 per cent of couples in private residences reported no other household members in 2001 compared with 64 per cent in 1971.

- Most widow(er)s lived alone after their spouse died and were increasingly likely to do so (76 per cent in 2001, up from 63 per cent in 1981).

- Around two out of three people under 45 were looking after dependent children at the census before their spouse died although their numbers declined in absolute terms between 1971 and 2001.

- The proportion of couples not sharing the same address at the census before one spouse died increased from three to nine per cent between 1971 and 2001, including couples where one or both members lived in communal establishments, as well as couples who had separated or were soon to be married. 


\section{Key findings}

- Most residential moves following the death of a spouse probably took place several years later rather than in the first 12 months or so after the death.

- An estimated three per cent of couples were not formally married to each other when separated by death.

\section{Acknowledgements}

The permission of the Office for National Statistics to use the Longitudinal Study is gratefully acknowledged, as is the help provided by staff of the Centre for Longitudinal Study Information and User Support (CeLSIUS). The authors wish to thank especially: Julian Buxton, Research and Computing Support Officer at CeLSIUS, for assistance in preparing data sets and offering advice on the analysis; and Rachel Stuchbury, Research and Computing Support Officer at CeLSIUS, for reading an earlier draft of this article and offering valuable comments. CeLSIUS is supported by the UK Economic and Social Research Council Census of Population Programme (Award Ref: RES-348-25-0004). Census output is Crown copyright and is reproduced with the permission of the Controller of HMSO and the Queen's Printer for Scotland. This study was approved by the ONS Longitudinal Study Research Board (Project 30093B). The authors alone are responsible for the analysis and interpretation of the data reported here.

\section{References}

1 Dunnell, K (2008) 'Ageing and mortality in the UK: National Statistician's annual article on the population'. Population Trends 134: 6-23.

2 Corden A, Hirst M, Nice, K (2010) 'Death of a partner: financial implications and experience of loss'. Bereavement Care 29: 23-28.

3 Brassett-Grundy, A (2003) LS User Guide 20: Researching Households and Families Using the ONS Longitudinal Study. Office for National Statistics and Centre for Longitudinal Studies, Institute of Education, University of London, London.

4 Blackwell, L, Lynch, K, Smith, J, Goldblatt, P (2003) Longitudinal Study 1971-2001:

Completeness of Census Linkage. Series LS 10, Office for National Statistics and Centre for Longitudinal Studies, Institute of Education, University of London, London.

5 Widow(er)hoods by sex 1971 to 2004. Available at: www.ons.gov.uk/about/who-we-are/ourservices/longitudinal-study/data-quality/event-sampling-and-linkage/widow-er--hoods/index. html\#Equation

6 Deaths of registered same sex partners have been recorded in the LS following implementation of the Civil Partnership Act (2004), which legally recognised registered same sex partnerships in the UK. 
7 Cases where there was a discrepancy between the main LS and widow(er)hood files in the sex of the deceased spouse were excluded. The 2001 bereavement cohorts also exclude cases with imputed age values, students not at their term-time address, and LS members with initial extract records only.

8 Hirst, M, Corden, A (2010) Trends and Changes in Household and Personal Circumstances on Death of a Partner in England and Wales, 1971 to 2001. Social Policy Research Unit, University of York, York.

9 Murphy, M, Grundy, E, Kalogirou, S (2007) 'The increase in marital status differences in mortality up to the oldest age in seven European countries, 1990-99'. Population Studies 61: 287-298.

10 Office for National Statistics (2006) 'Health expectancies in the UK, 2002'. Health Statistics Quarterly 29: 59-62.

11 Some married and cohabiting couples in the post-bereavement cohorts could have been living together before the LS member's spouse died.

12 Uren, Z, Goldring, S (2007) 'Migration trends at older ages in England and Wales'. Population Trends 130: 31-40.

13 Office for National Statistics (2003) Deaths by age, sex and marital status, 2001. Table 9 in Series $\mathrm{DH} 1$, no 34.

14 New widow(er)s statistics for England and Wales, 1939 to 2003, are compiled by ONS from mortality statistics and published as follows: New widowers data set (PMH61A) available at: www.statistics.gov.uk/StatBase/xsdataset.asp?vlnk=5287\&Pos=\&ColRank=1\&Rank=224 New widows data set (PMH61B) available at:

www.statistics.gov.uk/StatBase/xsdataset.asp?vInk=5288\&Pos=1\&ColRank=1\&Rank=208

15 Office for National Statistics (2009) 2008-based National Population Projections. Office for National Statistics, London. Available at:

www.statistics.gov.uk/StatBase/Product.asp?vlnk=8519

16 Office for National Statistics (2009) '2006-based marital status and cohabitation projections for England and Wales'. Population Trends 136: 112-120.

17 Department of Health (2008) End of Life Care Strategy. Promoting High Quality Care for All Adults at the End of Life. Department of Health, London.

18 Law Commission (2007) Cohabitation: the Financial Consequences of Relationship Breakdown $(\mathrm{Cm} .7182)$. The Law Commission, London. 